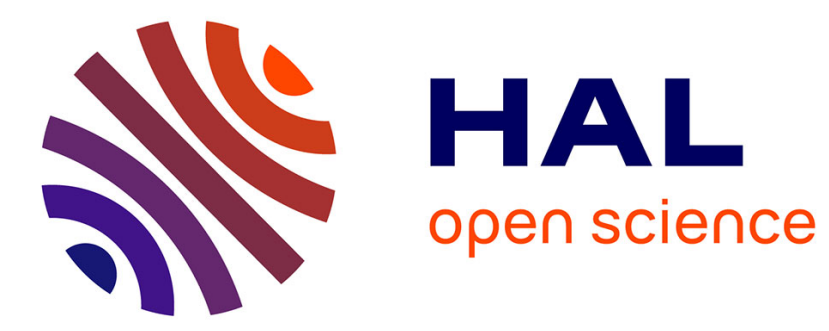

\title{
Biomechanical breast modelling to improve patient positioning during breast cancer radiotherapy.
}

Sylvain Vallier, Jocelyne Troccaz, Isabelle Gabelle-Flandin, Yohan Payan

\section{To cite this version:}

Sylvain Vallier, Jocelyne Troccaz, Isabelle Gabelle-Flandin, Yohan Payan. Biomechanical breast modelling to improve patient positioning during breast cancer radiotherapy.. Computer Methods in Biomechanics and Biomedical Engineering, 2013, 16 Suppl 1, pp.278-9. 10.1080/10255842.2013.815862 . hal-00854112

\section{HAL Id: hal-00854112 \\ https://hal.science/hal-00854112}

Submitted on 26 Aug 2014

HAL is a multi-disciplinary open access archive for the deposit and dissemination of scientific research documents, whether they are published or not. The documents may come from teaching and research institutions in France or abroad, or from public or private research centers.
L'archive ouverte pluridisciplinaire HAL, est destinée au dépôt et à la diffusion de documents scientifiques de niveau recherche, publiés ou non, émanant des établissements d'enseignement et de recherche français ou étrangers, des laboratoires publics ou privés. 


\title{
Biomechanical breast modeling to improve patient positioning during breast cancer radiotherapy
}

\author{
S. Vallier ${ }^{\dagger}$, J. Troccaz ${ }^{\dagger}$, I. Gabelle-Flandin ${ }^{\ddagger}$ Y. Payan*† \\ $\dagger$ Laboratoire TIMC-IMAG, France; $\$$ CHU de Grenoble, France
}

Keywords: Finite Element model; breast soft tissues; partial breast irradiation; breast phantom.

\section{Introduction}

Accelerated partial breast irradiation (APBI) is being studied as an alternative to whole breast irradiation for cases of early stage breast cancer. Delivering higher doses to more localized volumes demands high accuracy guarantees in order to treat the target volume adequately and to spare healthy tissues and organs at risk.

An offset in the patient position compared to the position in the planning CT scan can lead to under dosed volumes increasing the risk of recurrences or can result in more lung or heart volume irradiated, increasing the risk of treatment complications. Accurately positioning the patient on the treatment table is therefore very important. This paper introduces the breast phantom that was developed to quantify the positioning accuracy during radiotherapy.

\section{Methods}

The aim of using a phantom was to be able to realize multiple acquisitions and to evaluate the accuracy of the positioning technique itself, without the interference of breathing and patient motion uncertainties. Maximum precision regarding patient setup on the treatment table must be the first priority study before focusing on other sources of uncertainty. Using a phantom the closest to clinical anatomical reality allows realizing multiple acquisitions of a perfectly similar anatomical breast throughout the treatment process, and evaluating the precision of the positioning on itself, without any other source of artefact.

Mechanical properties of the breast phantom and choice for the breast/bust connection type

We decided to build a phantom with a $600 \mathrm{~cm}^{3}$ deformable breast fixed onto a polystyrene bust. This volume was assumed to represent a reasonable size for a breast, i.e. large enough to expect breast deformations within the order of one centimeter when the phantom is placed on the side. Larger volumes with corresponding higher deformations will be studied in the future. Two questions were then raised as concerns the design of this phantom: (1) Assuming that the breast tissues are made of a thin layer of stiff epidermis/dermis tissues (the skin) enveloping softer subcutaneous and glandular tissues, what mechanical properties should be provided to the corresponding materials in the breast phantom and what would be the optimal skin thickness? (2) How should the breast phantom be fixed to the polystyrene bust?

In order to answer to these questions, we developed a virtual model of the phantom defined by a Finite Element breast model. Responses to question (1) should be provided by tuning the skin thickness and the elastic parameters of the elements that model the epidermis, dermis, subcutaneous and glandular tissues. Question (2) should be solved by modifying the boundary conditions that describe the attachment of the breast model onto the rigid bust.

The breast morphology (left breast) was recorded using an optical localizer (Polaris from NDI Inc.) and a digitizer. The breast volume was then meshed using a hexahedron-dominant mesh generator (Lobos et al., 2010), able to distinguish surface elements (that represent epidermis and dermis tissues) and elements inside the volume associated to subcutaneous and glandular tissues.

\section{Results and Discussion}

A coherent global deformation of the breast under gravity was observed with the corresponding mechanical parameters, thus responding to question (1): a $0.5 \mathrm{~mm}$ skin thickness with a Young modulus (i.e. stiffness) for breast subcutaneous and glandular tissues around $20 \mathrm{kPa}$ (Krouskop et al., 1998) while the tissues enclosed in the skin envelope (epidermis and dermis) get a $100 \mathrm{kPa}$ value for the Young modulus (Liang \& Boppart, 2010; Diridollou et al., 2001). Finally, since human tissues can be considered as quasi-incompressible as they are mainly composed of water (Fung, 1993), a 0.49 value was chosen for the Poisson Ratio of the material. To provide a response to question (2), we had to look at the connection between the breast and the thorax. Anatomically, subcutaneous and glandular tissues composing a human breast are not tightly connected with the surrounding skin, allowing these tissues to spread underneath the skin surface. This phenomenon is a major reason for such high deformability and motion of breast with position changes. To try to fit as close as possible to 
this reality, two boundary conditions (i.e. the connections between the breast and the underlying thorax) were implemented and tested with the Finite Element model: a full adhesion and a central band thorax adhesion between the breast phantom and the polystyrene bust.

Figure 1 shows the breast model deformations facing a $45^{\circ}$ inclination gravity load for two different skin thicknesses (top panels) and with a partial (lower left panel) and a full (lower right panel) adhesion.

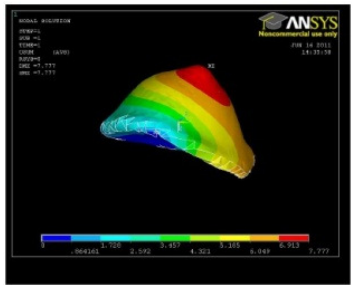

Central band fixation $e=0,5 \mathrm{~mm}$

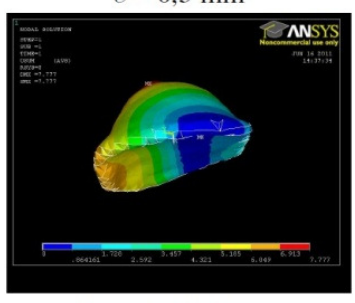

$\mathrm{D}_{\max }=7,777 \mathrm{~mm}$

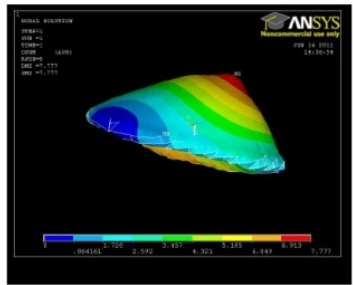

Full thorax adhesion $e=0,5 \mathrm{~mm}$

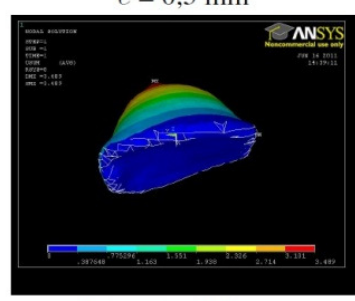

$\mathrm{D}_{\max }=3,489 \mathrm{~mm}$
Figure 1: Displacements of the breast Finite Element model facing a 45 degrees gravity load, with different skin thicknesses (top panels: $0.5 \mathrm{~mm}$ and $2 \mathrm{~mm}$ ) and with two boundary conditions for thorax adhesion (low panels: central band (left) and full adhesion (right)).

The central band thorax adhesion and a $0.5 \mathrm{~mm}$ thickness for the skin seem to provide the most realistic behavior of the breast model since a displacement close to $8 \mathrm{~mm}$ was observed in that case, qualitatively corresponding to what is observed in practice. It was therefore decided to use such thickness and boundary conditions in the physical design of the breast/chest phantom.

\section{Breast phantom construction}

A silicon RTV-EC00 material was chosen to represent the epidermis/dermis (material \#1) and the subcutaneous/glandular tissues (material \#2). By varying the concentration in base or catalyst making the silicon, the global stiffness of the materials was impacted. An aspiration device (Schiavone et al., 2010) was used to determine the adequate concentrations for both materials in order to get the values provided with the finite element model (i.e. $100 \mathrm{kPa}$ for material \#1 and $20 \mathrm{kPa}$ for material \#2). Figure 2 plots the corresponding breast phantom. A central band (part of which can be seen in black on that figure) was used to fix the breast phantom onto the polystyrene bust.
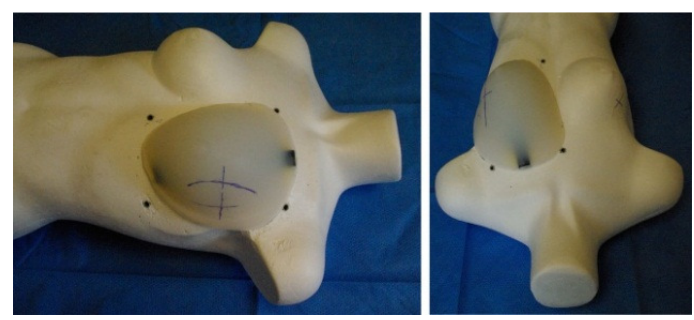

Figure 2: Breast phantom (silicon material) fixed onto a polystyrene bust with a central band

\section{Conclusion}

This dedicated phantom has been recently used to quantify the positioning accuracy during radiotherapy. In particular the influence of breast deformations onto the precision of the isocenter position is studied. For this, the phantom is positioned on the treatment table several times using skin marks laser alignment with the same standard contention system as for the planning CT scan. As a perspective, the Finite Element model might be used to assist the clinician in order to predict (and to compensate) breast deformations as discussed in Han et al., 2012.

\section{Acknowledgments}

We are grateful to the teams from the Radiation Oncology Department of the Grenoble University Hospital. This work was funded by CAMI Labex.

\section{References}

Diridollou S, Vabre V, Berson M, Vaillant L, Black D, Lagarde JM, Grégoire JM, Gall Y, Patat F. 2001. Skin ageing: changes of physical properties of human skin in vivo, Int. Journal of Cosmetic Science, 23:353-362.

Fung Y.C., Biomechanics: Mechanical Properties of Living Tissues, Springer, New York, 1993.

Han L, Hipwell J, Tanner C, Taylor Z, Mertzanidou T, Cardoso J, Ourselin S, Hawkes DJ. 2012. Development of patient-specific biomechanical models for predicting large breast deformation. Phys Med Biol. 57(2):455-472.

Krouskop TA, Wheeler TM, Kallel F, Garra BS, Hall T. 1998. Elastic Moduli of Breast and Prostate tissues under compression, Ultrasonic imaging; 20:260-274.

Liang X, Boppart SA 2010. Biomechanical Properties of in vivo human skin from dynamic optical coherence elastography, IEEE Trans on Biomed. Engineering, 57(4):953-959.

Lobos C., Payan Y. \& Hitschfeld N. Techniques for the generation of 3D Finite Element Meshes of human organs. Informatics in Oral Medicine: Advanced Techniques in Clinical and Diagnostic Technologies. Hershey, PA: Medical Information Science Reference, pp. 126-158, 2010.

Schiavone P, Promayon E, Payan Y, LASTIC: A Light Aspiration Device for in vivo Soft TIssue Characterization, Lecture Notes in Computer Science, 2010, Vol. 5958, pp. 1-10. 